DOI https://doi.org/10.18551/rjoas.2017-12.24

\title{
THE INTERNATIONAL MIGRATION TRENDS
}

\author{
Huang Y., Graduate Student \\ Vladivostok State University of Economics and Service, Vladivostok, Russia
}

\author{
Wiepcke C., Dr., Professor \\ Weingarten University of Education, Germany \\ Astakhova E., Candidate of Economic Sciences \\ Vladivostok State University of Economics and Service, Vladivostok, Russia
}

*E-mail: evastahova1@yandex.ru

\begin{abstract}
Migration is one of the most complex social phenomena. Usually migration flows are from less developed countries to more developed countries and, where there are quite favorable socio-economic conditions, namely - developed infrastructure, more high level of wages and working conditions, availability in the region affordable housing, transport accessibility, etc. Equilibrium in the labor market, reproduction of labor is a necessary condition for the full development of the economy. However, the available labor potential does not always correspond to the level of economic development orientation, so overcoming the deficit or excess of labor is the foundation in a dynamically developing economy, regardless of the type of socio-economic system. The analysis of the main trends in international migration is presented in the article. The changes in migration movements and in the foreign population of OECD Member countries are examined.
\end{abstract}

\section{KEY WORDS}

Labor, market, migration, OECD.

Regular migration can have positive demographic, economic and fiscal impacts for host countries. Migrants accounted for about half of the increase in the workforce in the United States and $70 \%$ in Europe over the past decade. They add human capital to host societies, but also bring new skills with them when they return or contribute as investors or entrepreneurs to the economy of their origin country. Available evidence also shows that in most countries migrants pay more in tax and social contribution than they receive in individual benefits. The magnitude of migrants' contribution however depends on the recognition and use of their skills in the labor market and more broadly on their labor market integration. Better integration outcomes are also a precondition for capitalizing on the migration-development nexus as there cannot be a positive impact of migration on origin countries unless immigrants are safe and making a decent living where they live. It is also conditioned on the capacity of the international community to fulfill its commitments in terms of reducing migration and remittances costs. The G20 Labor and Employment Minister's declaration paves the way for better policies and better integration outcomes for migrants.

Over 1 billion people in the world are migrants, or more than 1 in 7 people globally. The figure includes the stock of international migrants people residing in a country other than their country of birth whose number reached 244 million in 2015, up by 41 per cent since 2000; and it includes internal migrants around 740 million, 150 million are rural urban migrants in China. About 51 per cent of international migrants reside in 10 countries. The most popular destination country is the United States, where 46.6 million foreign-born officially resided in 2015, followed by Germany (12 million), the Russian Federation (11.9 million), Saudi Arabia (10.2 million), the United Kingdom (8.5 million), the United Arab Emirates (8.1 million), Canada and France (7.8 million each), Australia (6.7 million) and Spain (5.8 million). The top five countries by size of their diasporas (number of international migrants living abroad) in 
2015 were India (15.6 million), Mexico (12.4 million), the Russian Federation (10.6 million), China (9.5 million), and Bangladesh (7.2 million).

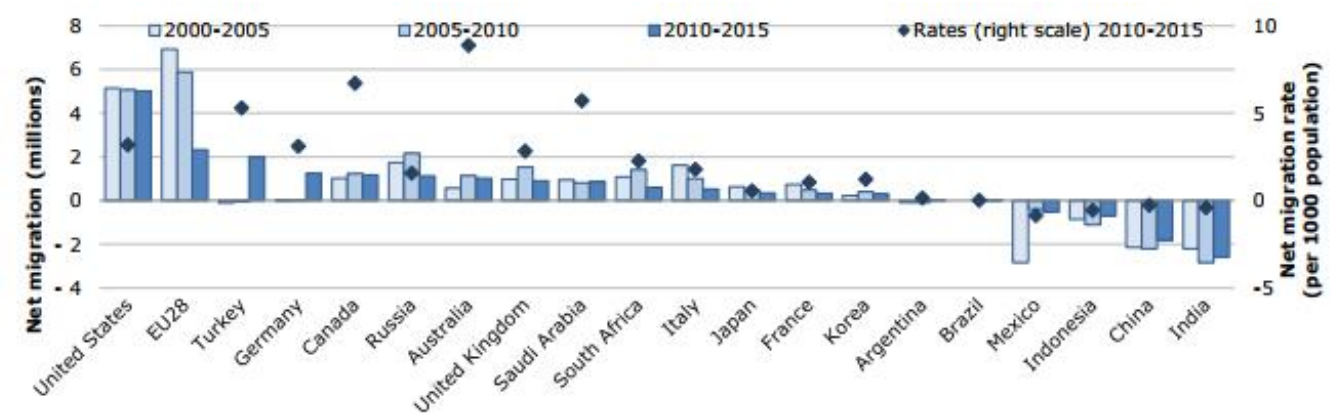

Figure 1 - Net migration to G20 countries, 2005-2015

The role of many countries and regions in the global migration order may fundamentally change over the coming decades, with some of the current major emigration countries potentially transforming into major destination countries. There is substantial evidence that as countries become integrated into the global capitalist economy they tend to go through migration transitions. It is particularly hard to predict whether these trends will continue, given that since the beginning of 2001 economic activity has experienced cyclical shocks of varying scales.

Parallel with broader demographic and economic transitions, several middle-income sending countries in North Africa and the Middle East (e.g. Turkey, Tunisia and Morocco), the Americas (e.g. Mexico, Brazil) and Asia (e.g. China, Thailand, Malaysia) may become major immigration countries, while the capabilities and aspirations increasing effects of human development in the poorest countries (such as in sub-Saharan Africa and South Asia) might boost emigration from these countries. This raises two fundamental questions: (1) how will population ageing and evolving economic dynamics affect the global demand for migrant labor and (2) where will future migrants come from?

Sending countries, in stark contrast with receiving countries, have increasingly linked migration to human development. The development impacts of migration are more positive in some cases and neutral or negative in some other cases. In fact, there is no automatic mechanism through which migration leads to more development. For instance, the migration of educated workers can deprive origin countries from the skilled labor that is essential for achieving sustained economic growth. Yet, there is a lack of systematic understanding of the complex interaction between these factors. Therefore it is necessary to better conceptualize the nature and relative weigh of migration uncertainties.

As shown in Figure 1 there are different layers of complexity in migration processes. While some factors can be considered as more or less exogenous, other factors are rather endogenous because they do not only affect migration, but are also affected by migration processes itself. These internal dynamics of migration processes (such as network formation) create feedback mechanisms which can give migration processes their own momentum (de Haas, 2008). With regards to model uncertainties, despite the progress made in recent decades, our understanding of the nature, drivers and feedback mechanisms underlying migration processes is still limited.

The above examples reveal two major uncertainties in our thinking about future world migration. First, model uncertainties are related to the still limited theoretical understanding of how social, economic, cultural and political factors affect the volume, direction and nature of migration. Second, contextual uncertainties pertain to the constantly changing macrocontextual situation in which migration occurs. In other words, this pertains to the direction the main factors affecting migration are likely to evolve in the future.

While we are familiar with a range of regularities in various spheres of social life, we remain largely uncertain about how future social, economic and political change will affect the contextual environment in which future migrations will take place. In order to imagine how 
such migration futures may look like, it is essential to think beyond current migration models and trends, and to become creative in imaging which fundamental changes on the global and international level may alter the macro-structure within which migration takes places. Such social, economic and political transformations may either confirm or invalidate (or both) the models with which we currently analyse migration. In other words, for a successful exploration we need to think "out of the box" and to conceive what we find difficult to imagine within the current context. For instance, it is often implicitly assumed that there is a quasiunlimited supply of cheap labor in developing countries ready to migrate to the West. The question is whether this assumption will hold in the future in view of global demographic change and economic growth in many developing countries.

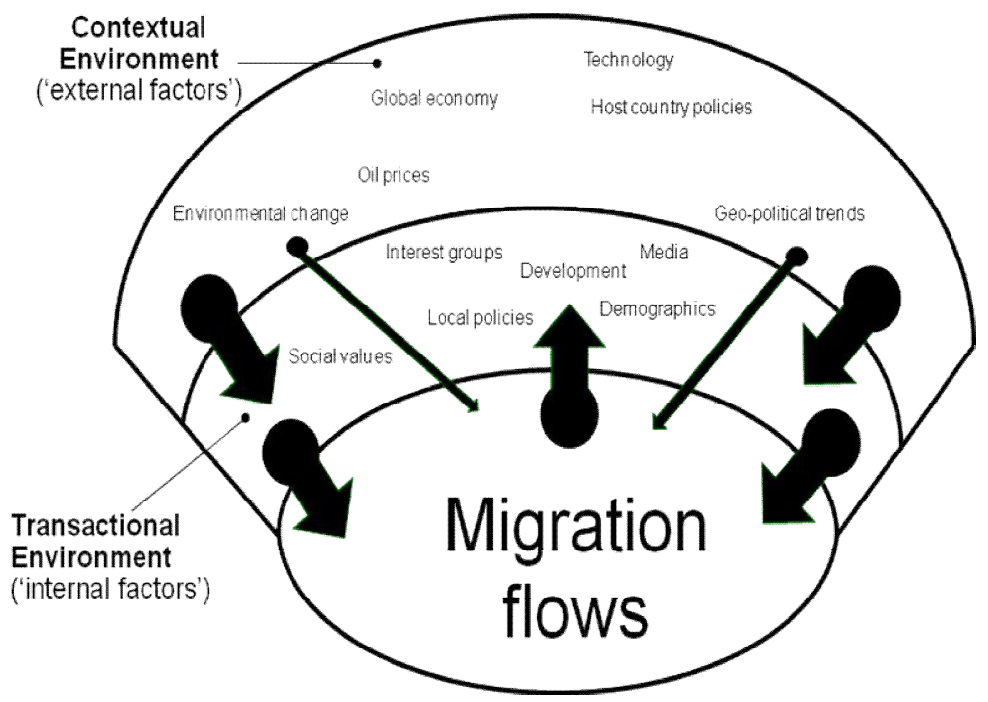

Figure 2 -Levels of Impacts and Feedback in the Migration Process

The west European experience with "guest-workers" is a case in point for the difficulty to perceive significant structural change and the discontinuities from past migration trends such transformations tend to cause. In the 1960s, the presumably "temporary" workers from Mediterranean countries were expected to return to their origin countries after a few years of work in Western Europe. The 1973 Oil Crisis sent shockwaves through European economies and formed the onset of a long period of economic recession, economic restructuring and rising unemployment, which also heralded the end of labor recruitment and the instauration of progressively restrictive immigration policies. However, the consequence was not a massive return or declining migration. Rather, as presented in Figure 2, many former "guest workers" decided to stay put in Europe, rather than face much more arduous and uncertain circumstances in origin countries. In addition, immigration restrictions paradoxically pushed migrants into permanent settlement. These processes set in motion large-scale family migration. As Max Frisch famously said "we wanted workers, we got people" or in Philip Martin"s own terms "there is nothing more permanent than temporary foreign workers" (Martin, 2001).

The guest worker case exemplifies that migration policies are often developed without sufficient consideration of the wider national and global context in which migration occurs, and how future changes and related sources of uncertainties in global demography, economic growth and environmental change may affect migration patterns in the long term.

Conventional approaches exploring the future of migration include the use of statistical analysis to analyze the previous trends, making assumptions about the main relationships with key "independent" variables and forecasting migration flows into the future. However, such approaches have several limitations. First, we must assume that the structure of our model remains the same across time. The structure is the relationship between migration and its main determinants. Second, the lack of data for many migration corridors often implies that parameters of projection models must be estimated using historical migration 
data for other countries. This obliges one to assume the structure does not change across countries and over time.

Nonetheless, even when there is data available, we still face significant model uncertainties because of poor theoretical understanding of the complex, multi-level drivers of the migration process. As a result of these limitations, too often future migration trends are explored using simple projections of current trends without taking into consideration future cultural, economic and environmental change on the global level. Such factors are likely to lead to fundamental changes in the direction, volume and complexity of international migration, but cannot be easily accounted for using traditional forecasting methods.

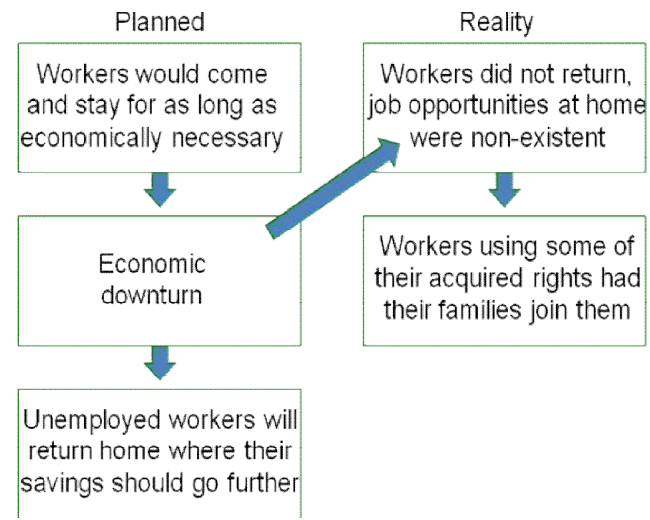

Figure 3 - The Planned and Actual Result of the Guest-Worker Programs.

Therefore, the general objective of the Global Migration Futures project is to explore future global and regional migration trends and their effects on European receiving countries and sending countries mainly located in Africa, Asia and the Middle East through the elaboration of scenarios. These scenarios will take into account future social, cultural, economic, political, demographic and environmental changes. In order to encourage innovative thinking about the future of migration, our distinctive methodology seeks to actively involve non-academic "stakeholders" (from business, policy, civil society, and elsewhere) in the development of scenarios.

Demographic factors, including geographically differentiated fertility levels and age structure are likely to have both an indirect and direct effect on the future of global migration. By implications, global and regional shifts in longevity, fertility and gender relations are likely to affect the global supply and demand for migrants. Such analysis has to be gender specific. For instance, among other things, the ageing process across wealthy countries, prolonged education and increased labor market participation of women have increased the demand for caregivers and various types of, often informal, labor. Concomitant changes in their labor market partly explain the increase in the number of independent female labor migrants. To add a further layer of complexity, the decrease in fertility rates seems to be a rather universal phenomenon. It can therefore be argued that the worldwide decrease in fertility rates may significantly reduce the relative (to demand) global and national supplies of high and low skilled labor migrants, potentially leading to generic wage increases of migrants. This may increasingly question the assumption underlying current migration models that there is a quasi-unlimited supply of cheap foreign labor (Piore 1979). The long-term effects of these two contradictory forces on the size of international migration remain unclear.

Economic factors, particularly international and national labor market structures and the future structure of global income and other opportunity differentials, are likely to exert a profound influence on future migration, although the direction is difficult to predict because of fundamental model uncertainties. We can only achieve an improved understanding of migration patterns by going beyond crude comparisons of mean income differentials, by considering the internal structure of economies and labor markets. For instance, labor markets are not homogeneous, but highly segmented. This can explain a sustained demand for migrant labor in particular segments of the economy, even under conditions of high formal 
unemployment and economic recession. In the past decades, particular sectors such as agriculture, construction, cleaning, gardening and catering have increasingly attracted migrant labor. However, depending on the nature of future changes in the global economy, migration might be affected in various ways. Trade and the outsourcing of economic activities to low-income countries may also have a decreasing effect on migration, and partly counterbalance the migration-facilitating effect of technological progress. At the same time, however, future economic growth in the poorest countries, for instance in sub-Saharan Africa and South Asia, can paradoxically have a migration-increasing effect because income increases may allow more people to migrate over large distances. Contextual factors are therefore sine qua non for understanding the shifting relation between economic factors and international migration.

The policy environment obviously exerts an important influence on migration. An emerging literature has demonstrated that migration policies significantly impact on the volume, directions and nature of international migration, although not always in the direction intended by politicians. For example, the relative increase of irregular migration over recent decades illustrates the limitations of policies to reduce migration along established migration corridors and, in turn, the shifting capacities of state to enforce entry and exit rules. Under such conditions, and particularly if economies of receiving countries are thriving, restrictions are more likely to influence the nature

Environmental factors are also frequently ascribed as having an important role on migration processes. Localized forms of environmental degradation (for instance, land degradation in semi-arid environments) and future global warming are often assumed to significantly affect global migration. Nevertheless, the existence, volume and directions of such effects are in fact highly contested. Some analysts believe that such crises may cause large-scale forced migration, creating international tensions and threatening social cohesion. But there is little empirical data on the coping strategies adopted by local communities as their environments change.

Between 2015 and 2016, the number of refugees in the 28 European Union countries increased by 273,000 to 1.6 million. During the same period, the number of refugees worldwide increased by 1.4 million, to 16.5 million. However, the European migration crisis appears to be abating. The number of people making the dangerous crossing to Europe has fallen from the record high in 2015. Yet, the fundamental drivers of distress migration persist.

Remittance flows were impacted by weak economic growth in Europe, the Russian Federation, and the Gulf Cooperation Council (GCC) countries (cyclical factors), and exchange controls, burdensome regulations, and anti-migrant policies in many countries (structural factors). Remittance flows, especially to South Asia and Central Asia, were affected by low oil prices and weak economic growth in Russia and the GCC countries. Weak growth in Europe also affected flows to North Africa and Sub-Saharan Africa. The weakening of the euro, the British pound and the ruble against the U.S. dollar further accentuated the decline in remittances in U.S. dollar terms. Remittance flows to the Europe and Central Asia (ECA) region registered a significant decline for the third consecutive year; these flows have fallen by 30 percent since 2013. Latin America and the Caribbean (LAC) was the only region to register an increase (6.9 percent) in remittance flows, supported by strengthening employment levels in the United States.

Although the overall remittance trend for developing countries was negative in 2016, the regional picture was more varied (table 1.1). The East Asia and Pacific (EAP) region registered a 1.2 percent estimated decline in remittances in 2016 , compared with 3.8 percent growth in 2015. Although flows to the Philippines remained buoyant, Indonesia saw a decline induced by new emigration restrictions. The South Asia region (SAR) witnessed an estimated decline of 6.4 percent in 2016. India, the largest remittance -receiving country

While labor migration is a universal phenomenon, some regions have far higher proportions of migrant workers relative to all workers: over one in three workers are migrant workers in Arab States, and about one in five in Northern America as opposed to 0.6 per cent in Eastern Asia (including China), and 1.5 per cent in Southern Asia (including India), Northern Africa and Latin America and the Caribbean. Close to one in five migrants in the 
world live in the top 20 largest cities globally, according to IOMs World Migration Report 2015; the report also found that in many of these cities migrants make up at least one third of the total population, and that migrants tend to concentrate in global cities for instance almost 50 per cent of Canada's foreign-born population lives in Toronto.

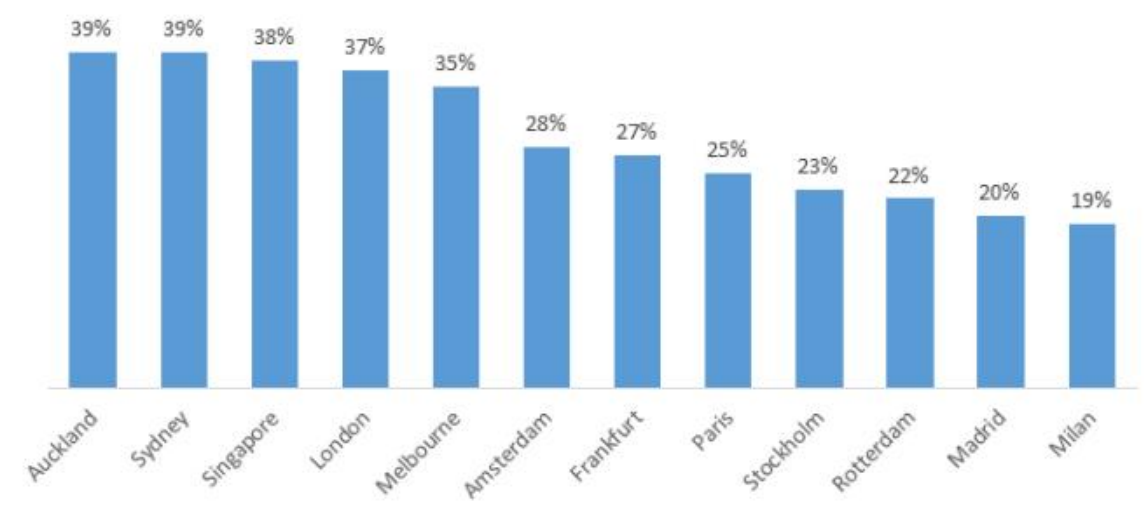

Figure 4 - Foreign born population in major cities

Furthermore, some countries, the U.S. being an example, are ideologically committed to open borders because their national identities are imbued with long histories of immigration. Those countries that haven't historically experienced immigration, primarily in Europe, tend to be less open to immigration. In these instances, social conflict may develop between native citizens and new arrivals, which may be understood as "polluting" national culture. It should be noted that regardless of their histories of immigration, the majority of migrant-receiving states tend to experience some backlash to large waves of immigration. On the other end, migrant-sending nations often benefit from remittances that result from higher wages in emigrant destination countries. However, these nations tend to experience "brain drain" of qualified and educated professionals, which negatively impacts their populations as well as their economic development.

Nevertheless, migration will continue to be a major, unstoppable factor of global life until the different push and pull factors associated with migration, including economic disparities between sending and receiving states are eliminated. Even as governments have attempted to limit cross-border flows of goods, services, capital and migration, the smuggling of human beings and resulting populations of illegal immigrants in both developed and developing nations have assumed a growing importance. Concerns over undocumented immigration have been tempered by the need for migrant labor, specifically in developed nations, as well as the existence of growing refugee populations, further complicating the creation of efficient migration policy. Dealing with both legal and illegal immigration, then, is one of the pressing issues facing governments and societies across the world.

\section{REFERENCES}

1. OECD-UNDESA (2013), World Migration in Figures, OECD/United Nations Department of Economics and Social Affairs, www.oecd.org/els/mig/World-Migration-in-Figures.pdf.

2. OECD-ILO-WB-IMF (2017) Towards a Framework for fair and effective integration of migrants into the labor market, G20 LEMM, 17-18 June 2017

3. Department of Economic and Social Affairs, Trends in International Migrant Stock: The 2015 Revision [Electronic resource] - Access mode: www.ilo.org/global/topics/labormigration/publications/WCMS_436343/lang--en/index.htm

4. Global Estimates 2015: People displaced by disasters. [Electronic resource] - Access mode: www.internal-displacement.org/publications/2015/global-estimates-2015-peopledisplaced-by-disasters 